\title{
RAPIDLY PROGRESSING DEMENTIA IN DISSEMINATED SCLEROSIS
}

\author{
BY \\ J. D. BERGIN \\ From the National Hospital, Queen Square, London, W.C.I
}

The mental and emotional changes associated with disseminated sclerosis have been known for almost as long as the disease has been recognized. All comprehensive reviews of this condition refer initially to Carswell's (1838) pathological specimen clearly showing the plaques of sclerosis and Cruvheilier's description of symptoms relating to one of his cases in his Atlas of Pathological Anatomy, published between 1835 and 1842 , this being considered the earliest overall account of the disease. Ombredane (1929) points out that two patients described by Cruvheilier had " psychic abnormalities". One was pictured as at times " seized with emotion difficult to describe " and to have " blushed and laughed and wept" as the examiner spoke to her, and the other was noted for impaired intelligence. In the pair there is an example of each of the two main psychological changes which have been stressed in subsequent accounts, namely, intellectual impairment and defective emotional control. Valentiner (1856) also described two cases with mental change and collected 13 from the literature. He remarked on the constancy of such changes when the brain was massively affected in disseminated sclerosis. Charcot (1868), whose classical description has led to the belief that it was the first account of disseminated sclerosis, delineated in his detailed study of the pathological anatomy and symptomatology the mental symptoms which might occur. He pictured the temperament of sufferers as cheerful and optimistic, stated that their emotional faculties were blunted, and noted intellectual impairment which particularly took the form of defective memory. He also discussed the mental symptoms in relationship to differentiation from dementia paralytica. Vulpian (1886) commented that although mental symptoms occurred, these were infrequent even in the cerebrospinal form, and much of the psychological disorder he attributed to the reaction any normal person would show to the disability accompanying the disease. He spoke, however, of " weakness of the memory, darkening of the intelligence, and sadness of the face". He stressed the rarity of mental symptoms, especially those gross enough to be confused with general paresis, and the late stage in the illness at which they occurred.

Some early accounts were confined to pointing the similarity of mental changes in disseminated sclerosis to those seen in general paresis, and Howes in 1927 found 25 reports of this nature in the literature. Guillain (1924), however, had already pointed out that cases of this type were all described before the introduction of either the lumbar puncture or the serological tests for syphilis, and Brain (1930) also drew attention to this at a later date.

Other early work mainly from French and German sources dealt with the psychological changes as a particular feature in disseminated sclerosis quite apart from any confusion with or differentiation from general paresis. Sugar and Nadell (1943) reviewed the literature and listed the great variety of symptom complexes which had been described, including dementia, emotional changes, psychoses, anxiety states, and hysteria.

Others, writing on the total picture of disseminated sclerosis without special consideration of mental features, have yet included reference to psychological changes. Thus Wechsler (1922) made a statistical survey of symptoms and signs in disseminated sclerosis. Among 191 cases mild memory defect and emotional change were frequent, impulsive laughter and euphoria were occasional, and marked dementia was rare. Brain (1930) in his comprehensive review of the whole subject pointed out that the mental symptomatology had received inadequate attention. He quoted the conclusion of the American Association for Research into Nervous and Mental Diseases (1921) that no particular psychic disorder is characteristic of disseminated sclerosis, but emphasized the subsequer.t findings of Cottrell and Wilson (1926) who observed some psychic disorder in all their patients. Sachs and Frieoman (1922) reported 141 cases, commenting on the great variability in the incidence of symptoms generally in earlier accounts. They found mental changes in $15.6 \%$. 
From the reports already considered it is clear that there has been much variation in opinion about the nature and particularly about the incidence of mental symptoms in disseminated sclerosis. Objective evidence of psychological defect developing during the course of the disease has, however, been provided by the application of psychometric tests during the course of the disease. Studies of this nature have been conducted by Canter (1951), by Pratt (1951), and by Ross and Reitan (1955). Canter's report is of interest because 23 of his 47 patients had previously had the U.S. Army General Classification test and by repeating it he showed the deterioration which had occurred after the onset of the illness in these cases.

It is intended here to describe a case of catastrophic dementia due to a cerebral disorder proved to be disseminated sclerosis, and a second case with similar clinical features in which post-mortem confirmation was not available.

\section{Case Reports}

Case 1.-This patient, D. M. (N.H. 48733), an unmarried woman aged 32, was admitted to the National Hospital, Queen Square, under the care of Sir Charles Symonds on January 13, 1954, and died in the mental observation ward of another hospital on March 31. There was no family history of nervous or mental illness.

In November, 1952, at the age of 30 , she had become aware of mistiness of vision in the right eye and found herself unable to see objects closely and there was an aching pain behind the eye. She remarked that red objects were particularly indistinct and that she had difficulty in recognizing the colours of the traffic lights. She attended the Royal Westminster Ophthalmic Hospital where a diagnosis of retrobulbar neuritis was made. Within a month her visual symptom had ceased to trouble her and she appeared to be in normal health. In October, 1953, she again complained of mistiness of vision and in addition thought she saw double on one or two occasions. She began, at this time, to feel vaguely ill and noticed that her right leg dragged as she walked. On medical advice she remained away from work for a month, but when she returned to her post her colleague commented on her unsteady gait. The difficulty in walking progressed until by 10 days before admission she was barely able to leave her bed and stagger to the lavatory. On several occasions during the two months before admission she noticed numbness in the left arm and less often a similar sensation in both feet. For a week micturition had been precipitate.

On account of the apathy and retardation shown by the patient when she was first seen special enquiry was made concerning her earlier mental state from those who lived in the same household. Her mother thought she had changed a little in a vague way, but neither her sister nor her brother had noticed such change. From her place of employment the supervisor stated that her work, which she had continued until three weeks before ad- mission, had been on the whole satisfactory. It had been apparent, however, that for temperamental reasons she had become less easy to work with and for this reason a change of post within the department had been arranged.

On examination the patient was a well nourished young woman, vague and apathetic. Although retarded she was correctly oriented and could speak of current events and personalities. Her memory was a little impaired on formal testing. The positive findings on physical examination were pallor of the left optic disc, fine nystagmus on horizontal deviation, slight right facial weakness, slight weakness of the right hand, and some weakness of both lower limbs which along with incoordination rendered her unable to stand. The deep reflexes were not particularly abnormal but both plantar responses were extensor. There was impairment of position sense and vibration in the lower limbs. Blood and urine tests were normal, and a chest radiograph was clear. The C.S.F. was abnormal, containing 18 cells, all lymphocytes; the protein content was $45 \mathrm{mg}$.; the colloidal gold curve was strongly paretic (5543210000).

The history and clinical features pointed to a diagnosis of disseminated sclerosis and the cerebrospinal fluid findings were consistent. At the time of admission she had been able to give a reasonable, though perhaps incomplete history, and could cooperate in answering a series of quite searching questions as well as in examination generally. A week after admission, however, strange behaviour developed. She became confused, disorientated, and uncooperative. Conversation became minimal and irrelevant. She was now doubly incontinent. Formal psychometric assessment at this time gave evidence of gross deterioration from a superior intellectual level, this affecting both visuospatial and verbal tests.

When she had been in hospital three weeks her confusion and dementia were so marked that the original diagnosis of disseminated sclerosis was clearly in doubt and some more massive demyelinating disorder was considered as a possible explanation for the clinical picture. In examination of her mental state at this time it was found that she was grossly confused, inattentive, and unable to understand simple questions. Specific tests of mental function given on admission and a week later were again repeated and poorer responses were elicited. Perseveration and retardation were manifest.

An E.E.G. (Dr. W. A. Cobb) (Fig. 1) on February 15 was markedly abnormal without localizing or focal features. There were random irregular slow waves from all areas. An air encephalogram was carried out on February 13 and showed the ventricular system to be normal in position but the ventricles to be moderately and symmetrically enlarged. The cerebrospinal fluid reexamined on February 19 was still under normal pressure, remained clear and colourless, but it now contained 37 lymphocytes and $30 \mathrm{mg}$. of protein per $100 \mathrm{ml}$. The Lange colloidal gold curve remained paretic (432111000).

By the end of February, six weeks after admission, deterioration in mental state had been of such degree that the patient now lay in bed, incontinent and making loud, whining and nasal noises, but uttering no recognizable words. She obeyed no commands and did not cooperate for nursing or examination. The only limb 


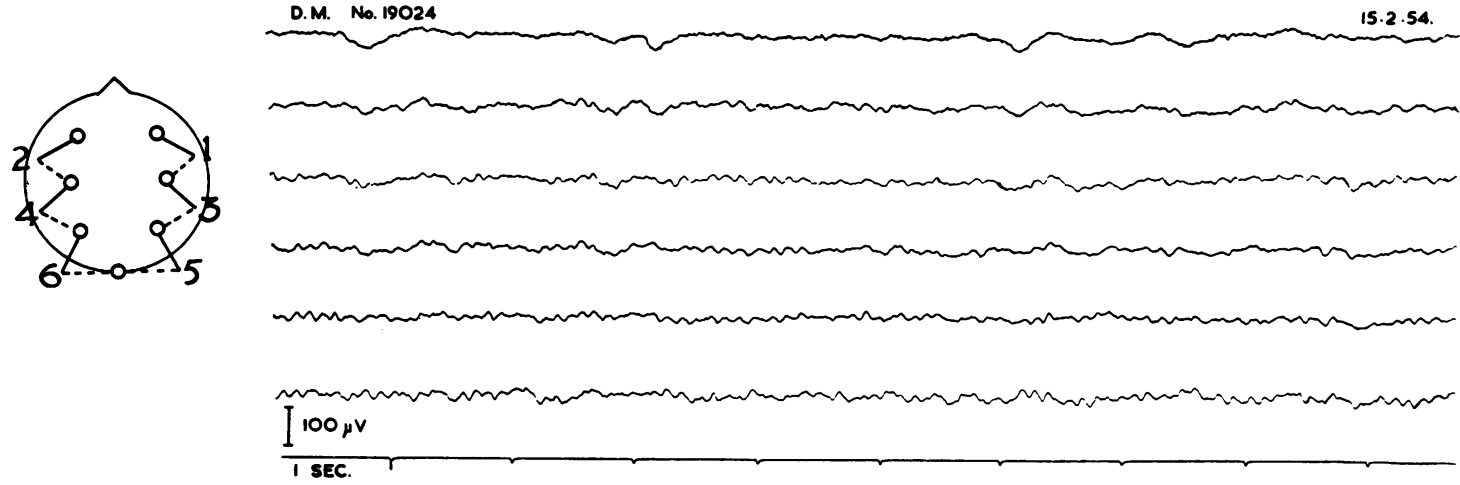

Fig. 1.-E.E.G. in Case 1 taken on February 15, 1954.

now active was the left upper and this she used to strike out at anyone who attended her, and to scratch her face or tug her hair. Constantly repeated wild hair pulling movements were a principal feature of any activity she showed. Dysarthria was gross.

By mid-March her limbs were practically motionless
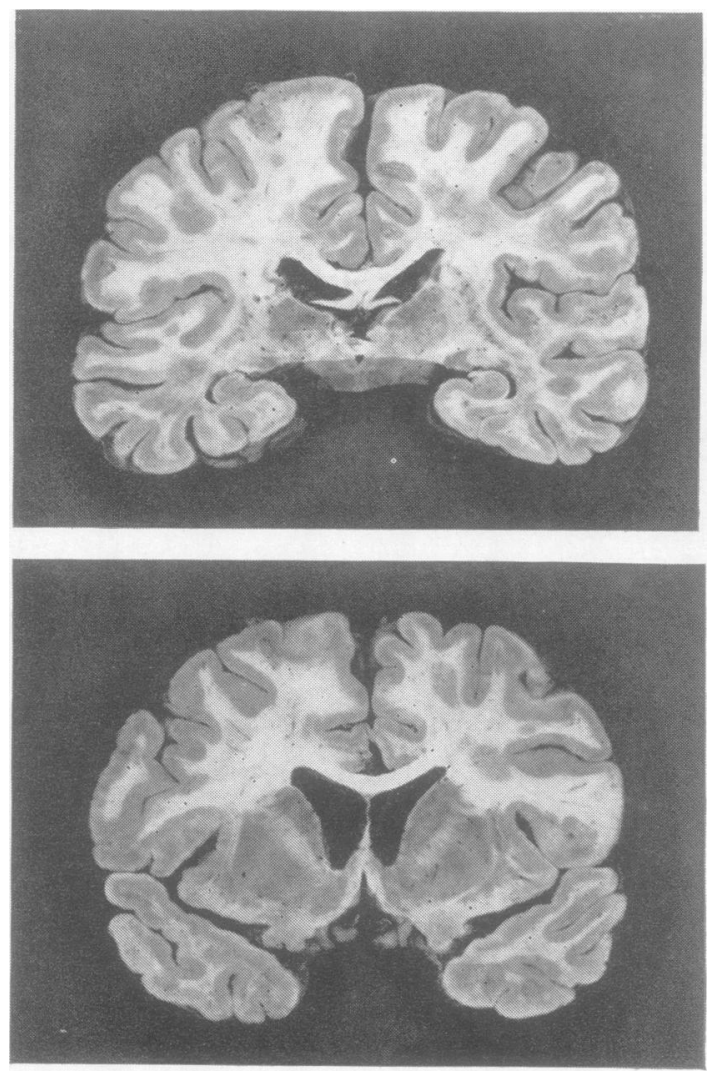

FIGs. $2 a$ and $2 b$.-Plaques in deeper layers of cortex and in subcortical white matter. and she lay in bed, still uttering loud, whining noises, clutching her hair and rolling her head from side to side. She was incontinent and now pyrexial. She remained in this state for a further fortnight when, because of her mental condition and the disturbance caused by her constant noisy utterances, she was transferred to an observation ward. Further deterioration occurred and she died a few days later and Dr. W. Blackwood's report on the necropsy reads as follows:-

On section all lobes of the cerebrum were the site of well-defined, rather smoothly outlined pinkish-yellowish or pinkish-greyish regions of demyelination. These plaques were present at the angles of the lateral ventricles but to a lesser extent than is usually seen in disseminated

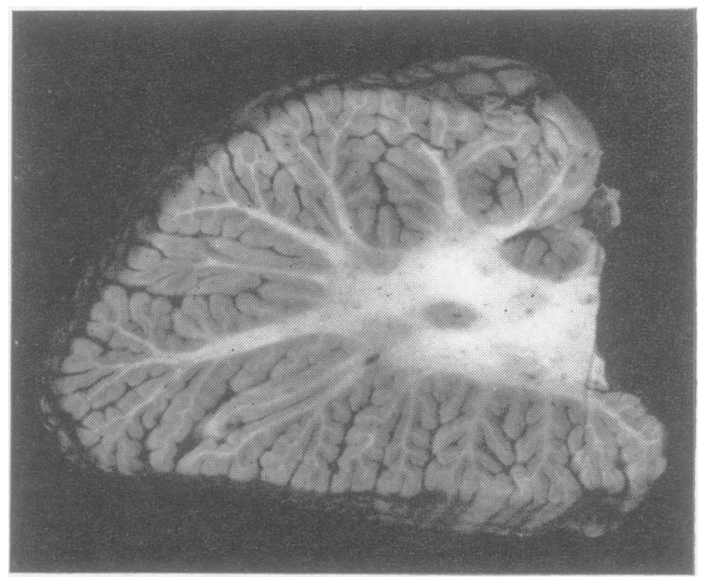

Fig. 3.-Plaque in white matter of the cerebellum.

sclerosis while the number of plaques in the deep white matter of all lobes and especially in the deeper layers of the cortex and subjacent white matter was very much greater than is usually seen (Figs. $2 \mathrm{a}, 2 \mathrm{~b}$ ). Plaques were visible in the cerebellar white matter in both hemispheres (Fig. 3). The optic nerves were thin but not obviously demyelinated. Several large yellowish plaques were present in the spinal cord. 
In the midbrain a triangular-shaped plaque with the base in the ventral half of the periaqueductal grey matter extended forward almost as far as the ventral sulcus. In the pons there were extensive lesions in the dorsal tegmental portion and in the pons proper. The medulla was extensively involved and the spinal cord showed plaques at many levels.

Microscopical examination showed the plaques in the cerebrum and cerebellum with loss of myelin sheaths but few axons staining. There was astrocytic hypertrophy, hyperplasia, and glial fibre formation. In recent plaques there was perivascular lymphocytic cuffing. Other plaques were quiescent.

Case 2.-This patient (R.S. N.H. No. 44463), a married woman aged 24, was admitted to the National Hospital under the care of Dr. E. A. Carmichael on April 7, 1953. At the time of admission she was in a state of abnormal consciousness and unable to cooperate in any way. Her previous health had been good and there was no knowledge of familial disease. Twelve months previously the eyesight in one eye became blurred and after a month returned to normal. She was then in the early stages of pregnancy, and subsequently passed normally to term and delivered a healthy child. The husband stated that from the time of her first symptoms until her admission to hospital 12 months later there had been one day in every two or three weeks in which his wife did not seem quite her usual self. At these times she did not do the housework, became bad-tempered, and, he thought, seemed to care about nothing. She continued, however, to run her house and care for her husband and child until six weeks before admission when her eyesight again became disturbed and vision failed, this time in both eyes, so much so that her husband thought she had been quite blind for the past three weeks. When vision had again become impaired, weakness had developed in the right arm, and as she walked the right leg dragged.

On examination the patient was a young woman of slight build, recumbent, incontinent, staring vacantly and answering nothing. She made frequent, sudden, side-to-side rotatory movement of the head. The lips were lacerated. As one attempted to examine the cranial nerves she bit savagely at the examiner's hand or at test objects which were approached to her. Visual acuity could not be formally assessed. She appeared to see nothing placed before her, but blinked to a menacing movement. The right optic disc was normal in appearance, the left showed moderate pallor with clear-cut edges. The pupil reactions were those of a blind left eye.
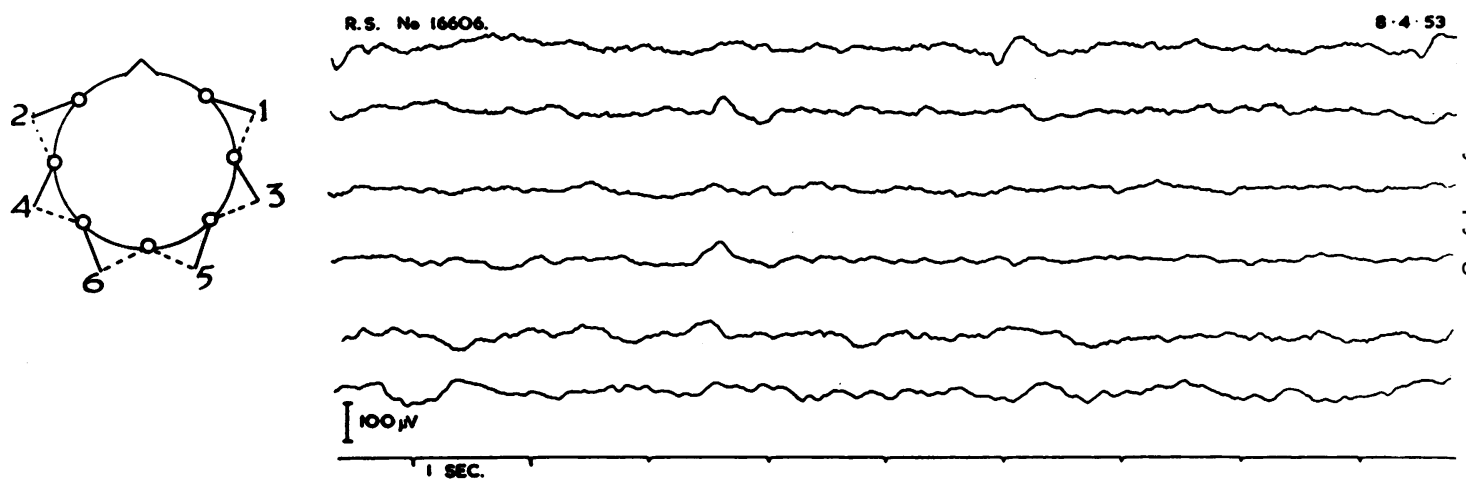

Fio. 4.-E.E.G. taken on April 8, 1953, showing low-voltage waves of wide frequency range and generalized distribution.
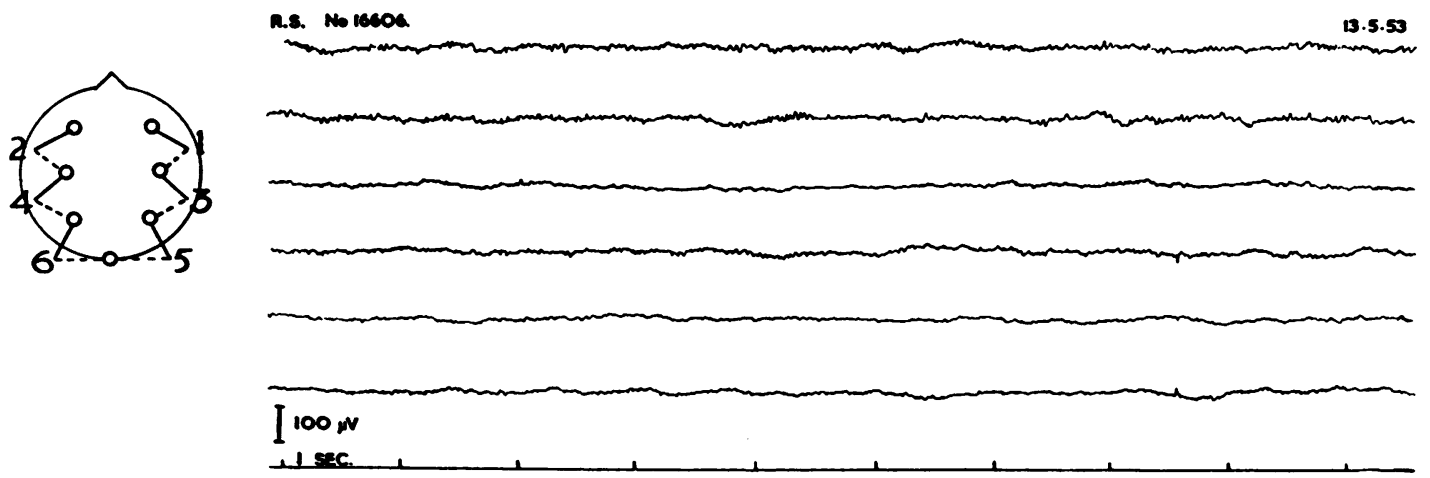

Fio. 5.-E.E.G. in Case 2 taken five weeks after that of Fig. 4. 


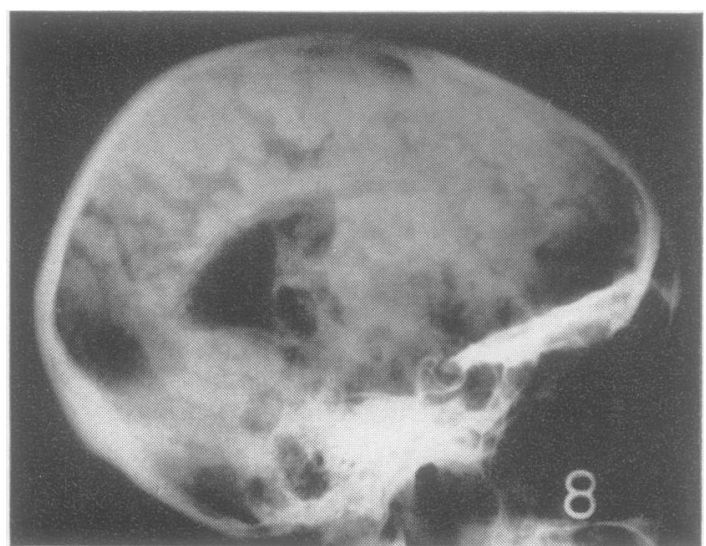

Fig. 6.-Air study in Case 2 showing dilated ventricles and large cortical collections of air.

There was total quadriplegia with increase of tone and reflexes in the lower limbs. The only sensory testing that was possible showed that painful stimuli were appreciated in all areas. There was a leucocytosis and some pyrexia, these attributed to an infected bedsore. The cerebrospinal fluid pressure was $85 \mathrm{~mm}$. and the fluid contained 7 lymphocytes and $45 \mathrm{mg}$. protein. The Lange curve read 1112221110. The Waspermann reaction was negative. An E.E.G. (Fig. 4) obtained with difficulty on April 8 was reported by Dr. W. A. Cobb to show no normal rhythms. The record consisted entirely of lowvoltage undulating waves with a wide frequency range which were generalized in distribution. A further record five weeks later showed negligible rhythmical activity (Fig. 5). An air encephalogram showed symmetrical dilatation of the lateral ventricles and the third ventricle was also dilated, measuring $1.4 \mathrm{~cm}$. in maximum width. A considerable quantity of air entered the subarachnoid space, particularly along the side of the falx, and the medial sulci were seen to be very much broadened (Fig. 6). The anterior end of the third ventricle was outlined and was not deformed. The aqueduct and fourth ventricle were normal in situation. The total appearance was that of diffuse atrophy.

After a week in hospital the patient remained in the same mental condition as on admission. She had not been heard to speak a single word. For hours at a time she rolled her head from side to side in a rapid, rhythmic manner and snapped with her jaws at all objects within reach. The bed linen at the head of the bed rapidly hecame torn as she clawed and pulled at it with her teeth. Her physical signs changed little; the quadriplegia remained severe, the spastic increase in tone became more marked and the reflexes more brisk. There was no change in behaviour in the next two months. At the beginning of June, however, she spoke more readily, but her answers to questions were completely unpredictable. By the end of May there had been some return of movement in the left upper limb and shortly after this a little voluntary movement in the right arm and both legs occurred. A month later she could move her left arm enough to strike the examiner and in a further two weeks she could sit out of bed. Improvement did not continue, but regression occurred and she again became confined to bed, quadriplegic and incontinent. Sometimes she would eat normally from a spoon, sometimes she would snap viciously at things. Two months later she remained grossly demented, disoriented, and abusive, and continued to tear sheets and her own clothes with her teeth and to snap at anything brought near her face. She became so noisy and abusive with so much screaming and shouting that it became impossible to keep her in an ordinary ward and she was transferred to a mental hospital in October, where she died a few weeks later. Necropsy was refused.

\section{Discussion}

Admission to Mental Hospitals. - Both the patients reported in this paper became demented to the extent of requiring admission to mental hospitals, which raises the question of how often such a measure becomes necessary in the course of disseminated sclerosis. Drefendorf (quoted by Ross (1915)) points out the rarity of symptoms of sufficient severity to warrant admission to a mental hospital. Stoddart, quoted by the same author commenting on Raymond's remarks about mental changes in cases he had seen at the Salpetrière, says that "We know from experience that disseminated sclerosis is practically never seen in asylums". Ross himself found five cases among the 750 in-patients then under care at The Royal Edinburgh Mental Hospital. Brown and Davis (1922) give the figures for patients suffering from disseminated sclerosis in the Manhattan State Hospital as three in a population of 6,700 . They qualify this by pointing out that the mental symptoms are often overlooked or not given special attention because of the physically disabling effects of the disease, and also that many whose mental state in mobile persons would require admission to a mental hospital are able to be nursed at home because of their inability to get about. Langworthy, Kolb, and Androp (1941) studied 199 cases of disseminated sclerosis attending their clinic over a period of 11 years. Thirty-seven showed obvious behaviour disturbance at some stage and 16 of the 37 were seriously enough affected to require admission to a mental ward. Sugar and Nadell (1943) considered the figures given for the occurrence of the disease among the inmates for admission to mental hospitals as of no help because the incidence of the condition among the population at large was unknown. Pratt (1951), however, asserted that the incidence of disseminated sclerosis among the inmates of mental hospitals was no greater than in the community generally, and in following up the progress of 544 cases of disseminated sclerosis 
actually found the incidence of certification lower than would have been expected from the population at large.

Electroencephalography.-The E.E.G. changes in disseminated sclerosis have been studied by a number of investigators beginning with Berger himself and including Freeman (1944), Hoefer and Gutman (1944), Bickford (1950), Jasper, Bickford, and Magnus (1950), Fuglsang-Frederiksen and Thygesen (1951) and Macrae and Aird (1954). All are agreed that E.E.G. changes are not well defined or pathognomonic of the illness and the only clear correlation is between the record and the acuteness of the phase of the disorder. The possible explanations for the E.E.G. abnormalities, which in the more marked form are of the pattern of diffuse and slow activity, are primary cortical cell change, disturbance of cortical activity by interference with afferent projection in the subcortical white matter or in the brain-stem, and possibly retrograde changes in the cortex as the result of disturbance of the efferent projection fibres in the white matter.

The site of the lesions responsible for the abnormality in the E.E.G. in the cases under discussion is likely to be the subcortical white matter where plaques of varying size were present in Case 1. The grey matter, and thus the E.E.G., would be secondarily involved; but the possibility may be considered of disturbance of consciousness and of the E.E.G. arising from lesions in the brain-stem. Thygesen (1953) stated that the symptoms of brain-stem involvement were nearly always reflected in the E.E.G., although he, too, considered more persistent cortical dysfunction as recorded in an E.E.G. as due mainly to subcortical plaques directly damaging the projection fibres.

Ventricular Dilatation.-Another feature of both the cases reported was the ventricular dilatation which in Case 2 (R.S.) was accompanied by considerable cortical atrophy. Zimmerman and Netsky (1950) found considerable hydrocephalus in three of their 50 post-mortem cases although one of these also harboured a cerebellar tumour. Brain (1930) refers to descriptions of internal hydrocephalus in disseminated sclerosis by Merle and Pastine (1910) and by Siemerling and Raecke (1914). He gives as possible explanations for its development atrophy of the hemispheres and obstruction of the aqueduct of Sylvius by surrounding sclerosis and ependymitis. The air studies in the two cases in the present paper and those done in other cases show that the aqueduct is not occluded and that cerebral atrophy is in fact present. Freeman (1944) reported 13 cases of disseminated sclerosis in which air studies had been carried out, and he could find only two other references in the literature to encephalographic studies in disseminated sclerosis, one relating to a single case without necropsy confirmation and the other to a series of six. Three of his own 13 cases were subsequently examined at necropsy. He found some dilatation of the ventricular system in most, although there was striking variability. The most characteristic finding in the air studies was a focal collection of cortical air, and he goes so far as to regard this as diagnostic of disseminated sclerosis if tumour can be excluded. Also the head of the caudate nucleus was flattened and the third and fourth ventricles were enlarged. He correlated the changes with clinical features: euphoria with dilatation of the anterior horns of the lateral ventricle; emotional changes and lethargy with dilatation of the third ventricle; and ataxia with dilatation of the fourth. He also drew attention to the frequency of necrotic plaques in the periventricular region and considered that contraction of these plaques was responsible for the dilatation of the ventricle. Cicatricial contraction in the subcortical plaques was likewise regarded as responsible for the cortical collection of air. Sachs and Freidman (1922) refer to a case in which ventricular dilatation was evident at necropsy. McAlpine (1955) comments on the presence of moderate hydrocephalus in long-standing cases without reference to its presence in the acute forms.

Pathology.-It is not intended to go in detail into the histological changes of demyelination, perivascular cellular accumulation, and subsequent gliosis. These features have been described many times. Of particular value are Dawson's (1914) monograph, an excellent account in Brain's (1930) review, and in the observations of Zimmerman and Netsky (1950) who examined histologically the nervous system in 50 cases which had come to necropsy after illnesses of duration varying from two months to 64 years. Their macroscopic observations were notable for the fact that a mild degree of hydrocephalus was present in many of the more long-standing cases. This finding was unusually severe in three cases although in the majority the ventricular system was unchanged. Regarding the distribution of lesions through the hemispheres, these were found, as they had been by others, symmetrically scattered in the central white matter but also in the cortical grey matter. There was a strong predilection for the periventricular site while the basal ganglia and corpus callosum were often involved. The paraventricular nuclei of the hypothalamus were affected at times and the lower brain-stem was also affected.

This leads to consideration of the correlation 
between pathological changes and mental disturbance in the cases reported here and in those of their kind. Cohen and Gavigan (1937) cite Philippe and Jonès (1899) as the earliest to maintain that specific mental changes were due to plaques of sclerosis scattered through the cortex and corpus callosum. Valentiner (1856) thought psychic disorder was constant when the brain was invaded by massive sclerosis, and Vulpian (1886), though he considered mental changes rare, gave them a basis of anatomical changes in the cerebrum. The same concept underlies the term "polysclerotic dementia" used by Dannenberger (1901). Langworthy and others (1941) attribute enfeeblement of intellect to interruption of subcortical fibres from plaques in the white matter, and they comment further that the position of plaques shows all possible variations, and disturbance of function may therefore be of all possible types. Cottrell and Wilson (1926) explained the affective changes in their cases on the basis of periventricular subependymal spread of pathological changes due to toxic invasion with particular involvement of the palaeothalamus. They contrast the relative integrity of intellectual function with relative conservation of the cortex unless the disease is far advanced. Sugar and Nadell (1943) consider the various pathological bases for the change of mental state: numerous plaques causing widespread interference with function, a general toxic infective condition, disturbance of the subcortical connexions of the cortico-thalamic and cortico-bulbar groups, thalamic involvement itself, meningo-fibrosis and cerebral atrophy. Having discussed these organic changes they go on to describe the mental changes as a reaction upon the part of the patient to his illness. Similar psychodynamic explanations have been propounded by Jelliffe (1921), by Borberg and Zahle (1946), and by Braceland and Giffin (1950).

In Case 1, which came to necropsy, the basis of the mental change and alteration of consciousness can be seen in the widespread lesions of the hemispheres and in the involvement of the brain-stem. This is in keeping with McAlpine's view (1955) that change in affect is unusual at or soon after the onset of the disease except in cases with widespread involvement of the brain-stem. He also says " as might be expected, evidence of intellectual deterioration is quite exceptional in the early stages of the disease, only occurring when there is other evidence of widespread cerebral involvement."

Admittedly, the second case may not be completely acceptable as disseminated sclerosis. There was a preliminary isolated retrobulbar neuritis and at one stage of the more advanced illness there was transient improvement. The degree of cerebral tissue change revealed in the air study, however, is sug- gestive of a more diffuse disorder such as one of the Schilders group. Should this be the nature of the condition the similarity of the clinical picture remains of great interest in view of the belief held by some that the demyelinating disorder is fundamentally identical in the two conditions, the diffuse changes in Schilder's encephalitis representing confluence of plaques which remain discrete in disseminated sclerosis.

\section{Summary}

Two cases are described in which there was a rapid onset of global dementia associated with the clinical signs of multiple lesions in the brain and spinal cord, leading to the diagnosis of disseminated sclerosis.

Investigation in both cases showed abnormal E.E.G. records, ventricular dilatation, and cortical atrophy.

Both patients had to be transferred to mental hospitals on account of their dementia, and the disease rapidly progressed to a fatal issue.

In one case the diagnosis of disseminated sclerosis was confirmed by post-mortem examination.

The rarity of dementia in disseminated sclerosis being of a degree requiring admission to a mental hospital is emphasized, and the significance of the air studies, E.E.G. abnormalities, and pathological lesions is discussed in relation to the mental disorder observed in these cases.

Grateful thanks are given to Sir Charles Symonds and to Dr. E. A. Carmichael under whose care these cases were admitted for permission to record them. Thanks are also due to Dr. W. S. Blackwood for the pathological material and to Dr. W. A. Cobb for the E.E.G interpretations.

\section{REFERENCES}

Bickford, R. (1950). Res. Publ. Ass. nerv. ment. Dis., 28, 422. Borberg, N. C., and Zahle, V. (1946). Acta Psychiat. Neurol. (Kbh.), $21,75$.

Braceland, F. J., and Giffin, M. E. (1950). Res. Publ. Ass. nerv. ment. Dis., 28, 450.

Brain, W. Russell (1930). Quart. J. Med., 23, 343.

Brown, S., and Davis, T. K. (1922). Arch. Neurol. Psychiat. (Chicago), $7,629$.

Canter, A. H. (1951). J. gen. Psychol., 44, 3.

Canter, A. H. (1951). J. gen. Psychol., 44, 3. Elementary Forms of Disease. Longman, Orme, Brown, Green and Longman, London.

Charcot, J. M. (1868). Gaz. Hôp. (Paris), 41, 554.

Cohen, L. H., and Gavigan, A. J. (1937). J. nerv. ment. Dis., 85, 266.

Cottrell, S. S., and Wilson, S. A. K. (1926). J. Neurol. Psychopath.,

Cruvheilier, J. (1835-42). Anatomie pathologique du corps humain. Baillière, Paris.

Dannenberger, A. (1901). Inaug. Diss. Giessen, p. 38.

Dawson, J. W. (1914). Trans. roy. Soc. Edinb., 50, 517

Freeman, W. (1944). Med. Ann. Distr. Columbia, 13, 1.

Fuglsang-Frederiksen, V., and Thygesen, P. (1951). A.M.A. Arch. Neurol. Psychiat., 66, 505.

Guillain, G. (1924). Rev. neurol. (Paris), 1, 648.

Hoefer, P. F. A., and Guttman, S. A. (1944). Trans. Amer. neurol. Ass., 70, 70.

Howes, S. F. H. (1927). Boston med. surg. J., 196, 310.

Jasper, H., Bickford, R., and Magnus, O. (1950). Res. Publ. Ass.

Jasper, $\mathrm{H}$., Bick. ment. Dis., 28,421 .

Jelliffe, S. E. (1921). Ibid., 2, 82. 
Langworthy, O. R., Kolb, L. C., and Androp, S. (1941). Amer. J. Psychiat., 98, 243.

McAlpine, D. (1955). Multiple Sclerosis by Douglas McAlpine, N. D. Compston, and C. E. Lumsden. Livingstone, Edinburgh and London.

Macrae, D., and Aird, R. B. (1954). Electroenceph. clin. Neurophysiol., $6,699$.

Merle, P., and Pastine, C. (1910). N. Iconogr. Salpêt., 23, 613.

Ombredane, A. (1929). Les Troubles mentaux de la sclérose en plaques. Presses Universitaires de France, Paris.

Philippe, C., and Jonès (1899). Rev. neurol. (Paris), 7, 798.

Pratt, R. T. C. (1951). Journal of Neurology, Neurosurgery and Psychiatry, 14, 326.

Ross, A. T., and Reitan, R. M. (1955). A.M.A. Arch. Neurol. Psychiat., 73,663 .
Ross, D. M. (1915). Rev. Neurol. Psychiat., 13, 361.

Sachs, B., and Friedman, E. D. (1922). Arch. Neurol. Psychiat. (Chicago), 7, 551.

Siemerling, E., and Raecke, J. (1914). Arch. Psychiat. Nervenkr., 53,385 .

Sugar, C., and Nadell, R. (1943). J. nerv. ment. Dis., 98, 267.

Thygesen, P. (1953). The Course of Disseminated Sclerosis. Rosenkilde and Bagger, Copenhagen.

Valentiner, W. (1856). Dtsch. Klin., 8, 147, 158, 167.

Vulpian, A. (1886). Maladies du système nerveux, Vol. 2, pp. 707-708. Doin, Paris.

Wechsler, I. S. (1922). Arch. Neurol. Psychiat. (Chicago), 8, 59.

Zimmerman, H. M., and Netsky, M. G. (1950). Res. Publ. Ass nerv. ment. Dis., 28, 271.

\section{THE AUGUST (1957) ISSUE}

The August (1957) issue contains the following papers:-

Experiences in the Treatment of Ruptured Intracranial Aneurysms. The Late Cecil A. Calvert.

On the Advantages of Opening Certain Intracranial Aneurysms. J. R. Gibbs.

Familial Calcification of the Basal Ganglia with Response to Parathormone. W. B. Matthews.

Some Experiences with Walton's Frequency Analysis of the Electromyogram. J. Fex and C. E. T. Krakau.

The Effect of Chlorpromazine on the Electroencephalogram of Epileptic Patients. Walter Fabisch.

Cholinesterase in Normal and Abnormal Human Skeletal Muscle. Evelyn B. Beckett and G. H. Bourne.

Tuberculous Meningitis. G. Donald W. McKendrick and R. J. Grose.

A Note on Transneuronal Atrophy in the Human Lateral Geniculate Body. F. Goldby.

A Study of Dyslexia. Elizabeth Warrington and O. L. Zangwill.

The Significance of Hyperkinesis in Lesions of the Anterior Striatum in Rhesus Macaccus. Eric A. Turner.

Ischaemic and Postischaemic Paraesthesiae in Motor Neurone Disease. E. W. Poole.

Metastatic Paraplegia of Prostatic Origin with Notes of a Case Occurring 28 Years after Suprapubic Prostatectomy. Lambert Rogers.

Proceedings of the Society of British Neurological Surgeons: 55th Meeting.

Book Reviews.

A number of copies are still available and may be obtained from the Publishing Manager, British Medical Association, Tavistock Square, W.C.1, price 12s. $6 d$. 